\title{
Effect of salt on the response of birds to sucrose*
}

\author{
JOHN G. ROGERS, JR., and OWEN MALLER \\ Patuxent Wildlife Research Center, Laurel, Maryland 20810 \\ and Monell Chemical Senses Center, University of Pennsylvania, Philadelphia, Pennsylvania 19104
}

\begin{abstract}
The preference of male red-winged blackbirds for solutions of sucrose and sucrose with $0.03 \mathrm{M}$ sodium chloride was tested, using a two-bottle choice test. Preliminary experiments demonstrated that the birds were indifferent to $0.03 \mathrm{M}$ $\mathrm{NaCl}$ in water. Both control and experimental animals exhibited indifference to the solutions at the lowest concentration and aversion at the highest. The data suggest that the added sodium chloride makes the sucrose stimulus more discriminable.
\end{abstract}

Sweet stimuli have commonly been assumed to possess a universal appeal to animals. However, experiments with cats (Carpenter, 1956), armadillos (Maller \& Kare, 1967), and some birds (Kare, 1965) have demonstrated that some species do not show a preference for "sweet" and that this generalization has definite limitations. Recently, the observation of indifference to sucrose by the domestic cat (Carpenter, 1956) has been challenged. Bartoshuk et al (1971) reported that cats prefer sucrose when it is offered as a mixture with $0.03 \mathrm{M}$ sodium chloride; these cats were indifferent to $0.03 \mathrm{M} \mathrm{NaCl}$ when it was offered as a choice with water. Bartoshuk et al (1971) used electrophysiological data that indicate a strong neural response to water to explain the cat's preference for sucrose under these conditions. This strong response to water, they conclude, masks the taste of sucrose and prevents a preference from manifesting itself. Their electrophysiological data further indicate that the addition of minute quantities of $\mathrm{NaCl}$ to deionized water suppresses the "water taste," and thus makes the sweet stimulus discriminable.

Many species of birds are indifferent to solutions of sucrose in a two-choice situation (Kare, 1965). Pigeons and chickens (Kitchell et al, 1959, pp. 143, 145; Halpern, 1962), the only species that have been tested both electrophysiologically and behaviorally, display strong electrophysiological responses to water and weak responses to $0.44 \mathrm{M}$ sucrose. Both species were indifferent to sucrose solutions in a two-choice situation. In the following experiment, the preference of birds for solutions of sucrose and for sucrose solutions that contained small amounts of $\mathrm{NaCl}$ was evaluated under conditions similar to those of Bartoshuk et al (1971).

\section{METHODS AND MATERIALS}

Eighteen male red-winged blackbirds (Agelaius phoenecius), weighing from 55.0 to $69.1 \mathrm{~g}$, were trapped at the Patuxent Wildlife Research Center near Laurel, Maryland. ${ }^{1}$ All birds then were individually housed in cages, $36 \times 41 \times 61 \mathrm{~cm}$, at a

*This investigation was supported by the U.S. Bureau of Sport Fisheries and Wildlife, Patuxent Wildlife Research Center. temperature of approximately $21^{\circ} \mathrm{C}$ and with a light cycle of $6 \mathrm{~h}$ light, $18 \mathrm{~h}$ dark. The birds were acclimated to our laboratory for at least 2 weeks before testing. Two glass drinking tubes were attached to the back of each cage approximately $5.5 \mathrm{~cm}$ apart and $2.5 \mathrm{~cm}$ above the floor. Food containers were placed at the front of the cage. The animals were maintained on a commercial diet (Purina Game Bird Flight Conditioner ${ }^{2}$ ) composed of $19.0 \%$ (minimum) protein, $2.8 \%$ (minimum) fat, and $12.0 \%$ (maximum) fiber.

The test solutions of sucrose were prepared 24 to $48 \mathrm{~h}$ before use either with deionized water or with a solution of $0.03 \mathrm{M}$ sodium chloride. All chemicals were of reagent grade.

The birds were assigned to two groups of nine birds each. The experimental group received a choice between sucrose in $0.03 \mathrm{M}$ $\mathrm{NaCl}$ and $0.03 \mathrm{M} \mathrm{NaCl}$. The control group received the sucrose in deionized water and had deionized water as the alternative. The various concentrations of sucrose $(0.1,0.2,0.4$, and $0.8 \mathrm{M})$ were presented in a random order, and each concentration was offered for a 6-h period during each of 4 consecutive days. Each set of 4 test days was separated by 3 rest days, during which only deionized water was available. The positions of the solutions were alternated daily during the tests to control for positional habits. The volume of solution ingested each day was measured to the nearest milliliter.

\section{RESULTS}

Food and fluid consumption were similar for both groups of birds before and after the testing period. In addition, a preliminary experiment demonstrated that the birds were behaviorally indifferent to $0.03 \mathrm{M} \mathrm{NaCl}$ when it was paired with deionized water.

Analyses of variance were performed on the differences between the volume of water or $0.03 \mathrm{M} \mathrm{NaCl}$ consumed and the volume of sucrose solution consumed to test for differences in responsivity to the sucrose. In addition, an analysis of variance on the total daily fluid intake of the birds was carried out.

The response pattern of both groups of birds to the sucrose solutions was similar (Fig. 1). Both groups exhibited indifference to the solutions at the lowest sucrose concentrations and aversion to the highest concentrations $(F=13.23, \mathrm{df}=3 / 64, \mathrm{p}<.01)$. When the salt concentration was increased to $0.06 \mathrm{M}$ and the sucrose concentration was held constant at $0.4 \mathrm{M}$, there was no preference for the sucrose. The concentration of sodium chloride was not increased further since concentrations above $0.06 \mathrm{M}$ have been shown to be 


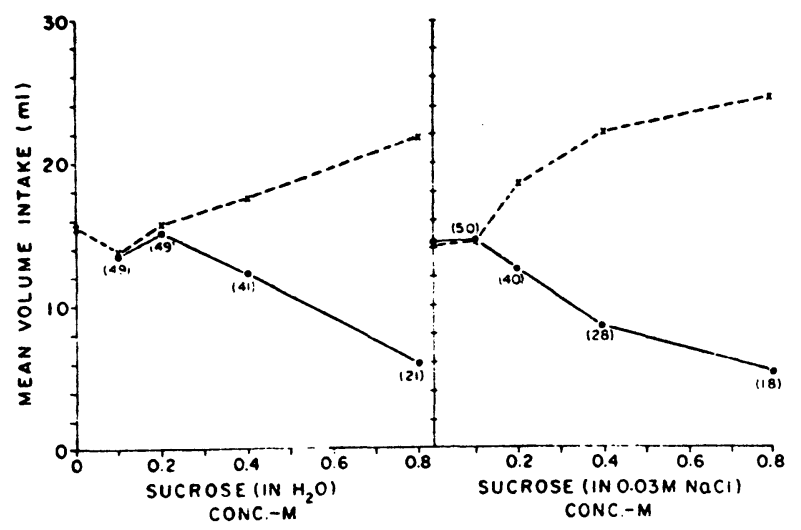

Fig. 1. Response of red-winged blackbirds to solutions of sucrose with deionized water or $0.03 \mathrm{M} \mathrm{NaCl}$ as the solvent. Solid lines represent sucrose intake, and dashed lines represent either water or $0.03 \mathrm{M} \mathrm{NaCl}$ intake; numbers within parentheses indicate the percent of sucrose in the total intake at each concentration.

aversive to birds (Pick \& Kare, 1962; Harriman \& Kare, 1966).

In addition to the similarity of effect of concentration on both groups, the data suggest a difference between the two groups in their preference for sucrose at 0.2 and $0.4 \mathrm{M}$ (Fig. 1). At $0.2 \mathrm{M}$, the birds in the experimental group seemed to reject the sucrose, whereas the controls consumed similar amounts of sucrose and deionized water. At $0.4 \mathrm{M}$, the experimental group rejected the sucrose to a greater degree than did the controls.

\section{DISCUSSION}

Contrary to the findings of Bartoshuk et al (1971) with the cat, our data indicate that the addition of small amounts of sodium chloride to solutiors of sucrose does not result in a preference for sucrose in the red-winged blackbird. These data clearly show that the redwing rejects sucrose and prefers water at concentrations of sucrose above $0.4 \mathrm{M}$, a concentration at which many mammals display an avidity (Carpenter, 1956) and to which many birds are indifferent (Kare, 1965). However, Jacobs and Scott (1957) offered a minority report indicating that chickens prefer a $0.35 \mathrm{M}$ sucrose solution but avoid a $0.13 \%$ saccharin solution.

The total fluid intake of the birds in our experiment was constant between groups and across all concentrations. This is in marked contrast to the tests with cats (Bartoshuk et al, 1971); they increased fluid consumption with increasing concentration in both the control and experimental tests. The increased fluid intake by cats could have resulted from the water loss produced by the diarrhea which was caused by sucrose ingestion.

Anderson (1954) demonstrated that $0.001 \mathrm{M} \mathrm{NaCl}$ lowered the taste threshold for sucrose in human Ss. One interpretation of the apparent difference in the responses of the two groups of red-winged blackbirds to 0.2 and $0.4 \mathrm{M}$ sucrose (Fig. 1) is that the combination of a small amount of $\mathrm{NaCl}$ with the sucrose makes the stimulus more discriminable.

It has been suggested (Duncan, 1960) that rejection of sucrose by birds may be due to viscosity. At high concentration, viscosity may play a part in the redwing's rejection of sucrose; however, there is probably no appreciable difference in viscosity between $0.2 \mathrm{M}$ or $0.4 \mathrm{M}$ sucrose in water and $0.2 \mathrm{M}$ or $0.4 \mathrm{M}$ sucrose in saline. The former appeared to be less objectionable to the birds than the latter. This indicates that the birds responded to the taste of the solution rather than to some other characteristic.

\section{REFERENCES}

Anderson, C. D. The effect of subliminal salt solutions on taste thresholds. Journal of Comparative \& Physiological Psychology, 1955, 48, 164-166.

Bartoshuk, L. M., Harnel, M. A., \& Parks, L. H. Taste of water in the cat: Effects on sucrose preference. Science, 1971, 171, 699-701.

Carpenter, J. A. Species differences in taste preferences. Journal of Comparative \& Physiological Psychology, 1956, 49, 139-144.

Duncan, C. J. Preference tests and the sense of taste in the feral pigeon (Columba livia Var. Gmelin). Animal Behaviour, 1960, 8, 54-60.

Halpern, B. P. Gustatory nerve responses in the chicken. American Journal of Physiology, 1962, 203, 541-544.

Harriman, A. E., \& Kare, M. R. Aversion to saline solution in starlings, purple grackles, and herring gulls. Physiological Zoology, 1966, 39, 123-126.

Jacobs, H. L., \& Scott, M. L. Factors mediating food and liquid intake in chickens. 1 . Studies on the preference for sucrose or saccharin solutions. Poultry Science, 1957, 36, 8-15.

Kare, M. R. The special senses. In P. D. Sturkie (Ed.), Avian physiology. Ithaca, New York: Cornell University Press, 1965. Chap. 14.

Kitchell, R. L., Ström, L., \& Zotterman, Y. Electrophysiological studies of thermal and taste reception in chickens and pigeons. Acta Physiologica Scandinavica, 1959, 46, 133-151.

Maller, O., \& Kare, M. R. Observations on the sense of taste in the armadillo (Dasypus novemcinctus). Animal Behaviour, $1967,15,8-10$.

Pick, H. L., \& Kare, M. R. The effect of artificial cues on the measurement of taste preference in the chicken. Journal of Comparative \& Physiological Psychology, 1962, 55, 342-345.

\section{NOTES}

1. The authors are grateful to Brooke Meanley, biologist at the Patuxent Wildlife Research Center, for supplying the test birds, and to Gail Seygal, of the Monell Chemical Senses Center, for excellent assistance.

2. Use of trade names does not imply endorsement of commercial products by the Federal Government.

(Received for publication January 19, 1973; accepted March 15, 1973.) 